Editorial

Recibido 21 de Mayo 2018, Aceptada 7 de Junio.2018, Publicada, 31 de Agosto 2018

\title{
Nuestro aporte femenino a la Reforma Universitaria
}

\section{Our feminine contribution to the University Reform}

\author{
Spadiliero de Lutri, $\mathbf{M}^{1}$ \\ ${ }^{1}$ Universidad Nacional de Córdoba, Facultad de Odontología
}

\begin{abstract}
This is a very special year for our National University of Córdoba, since we commemorate the centenary of the University Reform of 1918. The events that took place in our cloisters and driven mostly by students would mark a milestone in Higher Education of vital importance, not only in the National scope but that would transcend our borders towards all Latin America and the world.
\end{abstract}

KEYWORDS: University Reform, Feminine Contribution

\section{Resumen}

Este es un año muy particular para nuestra Universidad Nacional de Córdoba, puesto que conmemoramos el centenario de la Reforma Universitaria de 1918. Los hechos sucedidos en nuestros claustros e impulsados mayoritariamente por los estudiantes marcarían un hito en la Educación Superior de vital importancia, no solo en el ámbito Nacional sino que trascendería nuestras fronteras hacia toda América Latina y el mundo. 


\section{Introduction}

Este es un año muy particular para nuestra Universidad Nacional de Córdoba, puesto que conmemoramos el centenario de la Reforma Universitaria de 1918. Los hechos sucedidos en nuestros claustros e impulsados mayoritariamente por los estudiantes marcarían un hito en la Educación Superior de vital importancia, no solo en el ámbito Nacional sino que trascendería nuestras fronteras hacia toda América Latina y el mundo.

Nuevos paradigmas basados en una educación al alcance de todos, con igualdad de oportunidades, Cátedras libres, inclusión de nuevos sectores en el gobierno de la Universidad, dejaban atrás un concepto obsoleto y discriminatorio en el que solamente una elite o unos pocos "elegidos" podían acceder al ámbito Universitario que propiciaba la exclusión y la discriminación de gran parte del entramado social.

Haciendo un camino de retrospección histórica-evolutiva y tratando de proyectar mi mente hacia ese lejano tiempo y espacio, es dado pensar que una sociedad de principios del siglo $\mathrm{XX}$, no osaría contemplar el acceso y la participación de la mujer en la emisión de opiniones y menos aún en la toma de decisiones, reservadas solo a los varones.

No obstante, por ese entonces, asomaba la figura emblemática de Prosperina Paraván., una joven mujer de personalidad entusiasta entre los estudiantes universitarios, alumna de nuestra otrora Escuela de Odontología e integrante del Centro de Estudiantes, cuya participación según narra la crónica de aquellos tiempos tomaría especial relevancia en los hechos acaecidos en junio de 1918.

Un reciente artículo de Claudio Bustos y Leandro Carbelo, muestra la semblanza de esta mujer al expresar que:

Prosperina Paraván sentía lo que siente cualquier mujer que desafía los límites escritos o tácitos que impone la tradición de reservar los cambios universitarios a hombres. En su pedido de incorporación a la recientemente creada carrera de Odontología, no encontró objeción formal alguna, por lo que como se sabe, su voluntad y la de tres mujeres más, hizo la diferencia e ingresó a la Universidad Nacional de Córdoba.

Sus estudios comenzaron con un grave conflicto del que participaron otras mujeres, las Hermanas de la Caridad que como práctica menor, desarrollaban las funciones de custodias del internado del Hospital Nacional de Clínicas, además del de enfermeras.

Las monjas, llevaban un severo régimen en el espacio físico en el que los practicantes internos, podían pernoctar en el Hospital y para la época, las diez de la noche era el tiempo límite para el ingreso tanto para los que estarían de guardia como para los otros.

Los jóvenes habían invadido el Barrio que abrazaba el lugar, en numerosas pensiones, casas de familias y conventillos, por lo que con la vida, siempre viene la cultura que proveen los portadores de guitarras y bombos que llegaban del norte del país. Y, los practicantes, no serían distintos en el nuevo orden, por lo que con más alegría que años, llegaban a dormir luego que las monjas dieran doble cerrojo a la puerta de ingreso lateral al hospital.

Las Autoridades de la Facultad tomaron la decisión típica de la vieja Universidad cerraron el internado propiciando la restricción de derechos que enardeció al Centro de Estudiantes de Ciencias Médicas. Los integrantes del Comité Pro Reforma Universitaria, querían la creación de una Federación de Centros de Estudiantes como la que se produjo por esos días a nivel nacional con el surgimiento de la Federación Universitaria Argentina, promoviendo elecciones en todos las Facultades. En Ciencias Médicas lo eligieron a Enrique Barros, que estudiaba Medicina lo cual provocó cierto recelo en las Escuelas que tardíamente fundaron el Centro de Estudiantes de Farmacia y el Centro de Estudiantes de Odontología de la época. En esta última, decidieron que no adherirían a la Federación y mantuvieron una posición crítica con los reformistas.

Prosperina no coincidía con esas decisiones arbitrarias y de celos varoniles por el protagonismo político que no tenían otra explicación más que obviar la ola reformista que se vivía en la Córdoba del 18'. Más aun cuando producidos los hechos del 15 de 
junio, el Centro de Estudiantes de Odontología, que había sido rechazado y desconocido en la FUC, eligió una posición crítica para con ambos bandos en pugna, ella igualmente marchó por las calles y enfrentó la represión con una policía conservadora.

Alli pudo conversar con Enrique Barros, que auspició el acto de revelarse a la moral conservadora de reconocer a la mujer y acordaron convocar a la asamblea de estudiantes de Odontología para determinar si adherirían o no a la Reforma y a la FUC.

En marzo del 18' nadie se matriculó en protesta, Prosperina incluida, por lo que el Rectorado decidió más restricción y no dió inicio a las clases.

Así fue que el 19 de junio se reunieron los estudiantes de Odontología, en el Centro de Estudiantes de Ciencias Médicas y con la presencia de Prosperina, resolvieron aceptar con entusiasmo la invitación de la Federación Universitaria de Córdoba, para enviar a su seno, un delegado provisorio.

Con el triunfo de la Reforma y la asunción del Rector Eliseo Soaje, ella, como todos los reformistas, volvieron a las aulas porque el éxito de la gesta, también debía revalidarse en lo académico. Y aunque continuó vinculada al Consejo Consultivo de su Escuela, se iría perdiendo en el relato histórico que privilegió los prohombres románticos que posaron ese 9 de septiembre en el techo del Rectorado y que hoy constituye la imagen de la Reforma Lo cierto es que la política mantuvo su idea cerrada de "la cosa de hombres" hasta que otras olvidadas, hicieron posible la otra historia de la Reforma Universitaria que en su lucha libertaria, fue dejando postergado el principio de la igualdad con equidad para todos en la educación pública universitaria.

Por todo ello, nuestra Facultad de Odontología ha querido testimoniar su reconocimiento a esta mujer reformista, plasmando su recuerdo en este patio central de nuestra casa imponiéndole el nombre "Jardín del Centenario de la Reforma Prosperina Paraván".

Es de esperar que todos quienes a diario transitamos por este espacio destinado al esparcimiento, evoquemos su memoria perpetuándola como una acérrima defensora de los ideales que forjaron los paradigmas del respeto, la igualad y la inclusión, que solo da la convivencia en democracia.

Correspondencia a/Corresponding to; Prof. Dra. Mirta M Spadiliero de Lutri Facultad de Odontología. UNC Ciudad Universitaria. Córdoba. Argentina Haya de la Torre s/n. Pabellón Argentina Correo electrónicole-mail:mirta.lutri@unc.edu.ar 